\title{
THE IMPACT OF AACSB ACCREDITATION ON THE VALUE SYSTEM OF CLOSE TO THE STUDENT PROGRAMS
}

Robert E. Kemper, Northern Arizona University

Michael P. Bradley, Northern Arizona University

\begin{abstract}
$A A C S B$ accreditation is intended to be a measure of the quality of the output of Colleges of Business for their constituents. The AACSB has used surrogates to measure outputs in the past. This essay is a commentary on the effects that measuring inputs instead of outputs has had on the central value systems of accredited colleges. The power of the AACSB over the value system of an entire organization is illustrated with an actual experience.
\end{abstract}

\section{INTRODUCTION}

Winners. Everybody wants desperately to be a winner--be on a winning team. Organizations must be teams. These teams will be one hundred percent full, by left-brain standards, of highly "irrational" and emotional human beings. These human beings will thrive on the camaraderie of an effective and value driven small group or unit (13, p.60).

Further, these people will want to "stick out" on a winning team. They will want to feel that they are at least in partial control of their destinies. When these people are not in control, feelings of helplessness are paramount. Emotions prevail and small groups, we will call them brigades, band together for survival. The total left- and rightbrain research supports these hypotheses $(2 ; 7 ; 16)$.

\section{A SEARCH BY AND FOR ACADEMIC WINNERS}

Academic institutions need winners. And, winners seek academic organizations that respect the individual, that facilitate continued winning, that let people stand out--be "bugs of some importance." (15). How do winners know when they have found such an organization? Answer. They will recognize the winning organization by the values that drive the organization. A few of the basic values of winning organizations are (13, p. 285):

1. A belief in being the best.

2. A belief in the importance of the details of execution.

3. A belief in the importance of people as individuals.

4. A belief in superior quality and service.

5. A belief that most members of the organization should be innovators.

6. An explicit belief in and recognition of the importance of academic growth and individual development.

This essay allows the reader, a highly irrational and emotional human being, an opportunity to examine the impact of external organizations on an academic organization that lays claim to the above values. (See Exhibit 1)

But, we cannot talk about academic institutions unless we also talk of accreditation--about evaluating educational quality, about assuring institutional accountability, about achieving and maintaining high standards, and about making education more responsive to 
students' and society's needs. Yes, this essay is also about accreditation.

\section{EXHIBIT 1}

\section{Northern Arizona University Mission Statement}

Northern Arizona University is a comprehensive state supported public university with a single residential campus. As such, it seeks to maintain a balance in efforts relating to teaching, resear$\mathrm{ch}$, and service. While there is historic and continuing emphasis on teaching, the university has increased significantly its attention to research and service. Similarly, NAU continues to focus on undergraduate education while strengthening its graduate programs and adding to them in the best interests of the state, the university, and the students. The main goal is to achieve excellence in the full sense of a comprehensive public university. $(5, \mathrm{p} .3)$

\section{ACCREDITATION}

Accreditation is a rational process that must be applied to academic organizations which we described earlier as consisting of highly irrational people. What is true of people in academic organizations is also true of people in accreditation organizations. Both organizations have a similar goal-winning. And, winning is emotional. Every organization has its own point of view as to how winners are developed. Accreditation organizations seek to make winners of the academic institutions and the people in these institutions, including students, by insisting on quality and high standards for every aspect of higher education.

Accreditation is predicted on several important assumptions that must be made at the outset.

"Accreditation is a valuable--perhaps even essential--social tool whose usefulness and effectiveness have not been fully appreciated and whose full poten- tial has yet to be realized.

Accreditation began as a voluntary, nongovernment process and should remain so if its inherent values are to be preserved and enhanced.

Accreditation is a process that, at its heart, consists of guided self-evaluation and self-improvement and serves as a centerpiece to the little-understood, informal, but elaborate 'system' of selfregulation in post-secondary education.

Accreditation should be judged by its effectiveness in encouraging and assisting the institution to evaluate and improve its educational offerings. All other outcomes and uses of accreditation are secondary to this objective and should not undermine it. To be effective, accreditation must focus primarily on the institution or program, just as education must focus on the student.

Accreditation is highly vulnerable to misuse and abuse by those who wish to turn it to other purposes. But there are enough countervailing forces--individuals, institutions, associations, as well as accrediting bodies--to offset perversions of the process or power plays. The key, however, is a broader understanding of accreditation and agreement on its basic nature, purpose, and value." $(20$, p. $x)$

\section{AACSB}

Enter the American Assembly of Collegiate Schools of Business (AACSB). First the philosophy.

"AACSB accreditation fosters the attainment and maintenance of excellence in undergraduate and graduate education for business administration and accounting. The process evaluates business administration and accounting programs in terms of standards of performance recognizing the importance of diversity in higher education in management. The process is dynamic, and the interpretation of the standards 
is subject to change as environments, technology, circumstances and constituencies differ. Self-evaluation and peer evaluation by professionals, rather than regulation, provide the most effective assurance of accountability to our various publics. Institutions that successfully complete the accreditation review are identified as AACSB accredited for the appropriate types and levels of programs." (3, frontispiece).

The mission? "The American Assembly of Collegiate Schools of Business is an organization of colleges, universities, companies and other institutions committed to the advancement of education for business administration and management. The mission of the Assembly is to foster excellence in collegiate education for management. The Assembly pursues this mission through a variety of means including: Establishing and maintaining standards of quality for collegiate management education; conducting the broad and evolving process of accreditation; providing services that strengthen the capabilities of collegiate members engaged in management education; representing the interests of the membership to external constituencies; and facilitating interaction among parties interested in management education and development." (3, recto)

\section{THE FACULTY}

We hear you. So what? Everyone should have such a mission, you say. But, what about the faculty and AACSB? The answer, "The faculty as a whole shall be of sufficient number and shall demonstrate the capabilities, experience, professional involvement, instructional performance, scholarly productivity, and service essential for overall high quality." $(3$, p.25)

Again, so what? Now get this, "Scholarly productivity includes the quality and extent of research and publication." (3, p.25). Did the AACSB just say "publish or perish"? No, they did not. At least not until one of the
AACSB accreditation seeking universities gets a letter that states, "The data does reveal a relative absence of published research in the field of..."(19, p.2) And, not until one of the faculty members in this particular university was denied a promotion to full professor after the university's administration had read the AACSB report.

Emotional human beings, winning teams, group camaraderie, partial control of destinies, do you hear us? What that highly irrational faculty member is now thinking is, if I am going to get promotions and/or tenure, I need to be doing research. And if I am going to do research, I need to place less emphasis on my undergraduate classes, give less time to advising students, and teach larger sections so that I can gain release time for research. Now this is no problem unless you have been a part of an AACSB accredited business school that has emphasized teaching more than research.

What about the real life scenario forecast of an unsettled, and unsettling future? How does the reader come to terms with a simple but exciting concept of accreditation and the many complexities it has engendered for people who merely want to "stick out" on winning teams?

This essay continues with a "What if..." discussion on "the charge of the light brigade." To give credence to our "charge", we will be using Northern Arizona University, Flagstaff, Arizona for our setting. (See Exhibit 2.) But this "charge" could take place at any public supported, mid-sized university that traditionally places more emphasis on its undergraduate program than on its graduate programs.

The described faculty in our "charge" could be any faculty members among the hundreds across the United States who find themselves or could find themselves in a similar situation. Pic- 
ture a discussion situation between two un-tenured--one with an appropriate refereed publication record and a second with an excellent teaching record but a perceived inappropriate refereed publication record just after an AACSB on-site visitation. The result of the visitation and subsequent AACSB action is a one-year deferment with the possibility of probation if the scholarly research deficiencies are not corrected within one year.

\section{EXHIBIT 2}

\section{The Image of Northern Arizona University}

"To become educated is to become more human" has been adopted by the university as an expression of the image it constantly strives to create. Recognizing this principle, we of the Northern Arizona University faculty dedicate ourselves to maintain the highest standard of professional efficiency in a campus atmosphere of scholarship and friendliness. Furthermore, we feel that within and without the classroom the line of communication between the student and the faculty must be kept open, and the individuality of the student must be preserved. $(5, \mathrm{p} .4)$.

\section{THE CHARGE OF THE LIGHT BRIGADE}

To the right, the value driven university administration who has fostered over the years a quality, student oriented undergraduate program niche where teaching has been the number one priority. To the left, accreditation standards and guidelines which now highlights scholarly productivity in terms of research and publication. To the front, business college faculty, students, staff, fathers, mothers, and friends soon to be besieged by impersonal teaching complete with larger classes, fewer contact hours for major faculty, publish or perish frustrations, big buck research faculty versus not so big buck teaching faculty and other perceptions of AACSB standards. The challenge is to react positively to the immediate financial realities of AACSB and to survive them.

Thank God It Is Over. The "thank God the AACSB accreditation is over period" is not the easiest time for any Northern Arizona University (NAU) untenured faculty member who has just participated in an AACSB evaluation. Those who are un-tenured can easily be recognized because they are the ones sitting in their chairs looking out the window doing creative thinking. The window gazing may have started when they learned of the one year AACSB deferment. Mistakenly, these un-tenured faculty had thought that any new AACSB accreditation would be successful and so successful that a congratulatory letter from AACSB would even be etched in bronze just as a letter of congratulation was at the conclusion of a 1977 accreditation attempt $(6 ; 10)$.

Say What? Whereas during the height of the accreditation review and the pending decision by the AACSB, faculty refused to speak to anyone but the highest officials, we now are condemned to listen to people who ask:

"Lost your AACSB accreditation? Does that mean that my MBA will not be worth a damn?" (An MBA student who has just found out that our program may be put on probation within the new academic year).

"Got yourself put on AACSB deferment did ya? How does it feel to fall from the elite?" (An Arizona State University (ASU) vice-president jabbing an NAU vice-president who had jabbed an ASU vice-president when ASU's accreditation case was deferred a year earlier).

"Does this mean the 'Big Eight' accounting firms will not be coming to NAU to recruit because the program is now on deferment?" (A junior accounting major whose life long dream was to 
work for one of the elite accounting firms).

"Wow! What will the CBA have to do now to attract the better high school students to Flagstaff?" (A New Student Program Coordinator who previously persuaded several outstanding high school seniors to attend NAU just because the business program was AACSB accredited).

"How are we going to recruit top notch business faculty if NAU cannot support the current program?" (A management department search committee member reviewing a listing of recent Ph.D. graduates for a business policy faculty position).

"My dad just said that he spent $\$ 20,000$ for my business education. How am I going to tell him that the business program might be placed on probation?" (A senior business student who had persuaded her father that paying outof-state tuition at NAU would be worth it because the business program was one of only two hundred fifty-four (9) in the country that had AACSB accreditation).

New Priorities. We formerly tried to treat all students as a necessary ingredient for a successful undergraduate program. This meant that we would actually stop in a parking lot as well as in the corridors, and talk to any student who acted as if he or she wanted to talk. This phenomenon, which we valued more than gold, suddenly is ignored, and takes on a different value. Instead of considering students as an important component in the educational process, we now must regard them as time barriers to our scientific and scholarly production. In my case, students are one of the variables, (S), in the scientific formula on which I am working.

Willie, one of my colleagues, who had just returned from a one-year sabbatical spent at a large, fully ac- credited AACSB university and had missed the entire AACSB visitation and subsequent review and deferment, got very nervous when he saw my door closed. But, he could hear me thinking and breathing and was wise enough to buzz me on our new intercom after he had noticed that I had failed to answer a student knock at my closed door. Previously I had kept it open so that students would feel free to drop in for a visit concerning a class assignment.

"Does your door being closed have anything to do with the College's AACSB?"

"A big (Z) divided by a small (f)," I replied.

"Don't give me the big $(\mathrm{Z})$ divided by the little (f) crap. What happened to our development of high quality students that have learned values as well as technique and concepts so that they can make a contribution to society?"

"You minimize the (I) times (C) times (A)," I replied.

"And the diverse curriculum courses that are concerned with offering variety and challenge to students?"

"We must minimize (I)."

"And having courses that are rigorous? Ones that force students to exchange ideas with each other and the professor? What about those courses that are taught by a professor that has combined teaching and business experience and is able to allow the students to grasp the theory and see how it can be applied?"

"Willie, that was (I) times (C) times (A) and it must be minimized to maximize (Z) divided by (f)."

"What happened to the classes that were small enough to allow for the interaction of ideas, that challenged the students to learn to communicate and 


\section{EXHIBIT 3}

THE BIG RICHARD/AACSB FORMULA

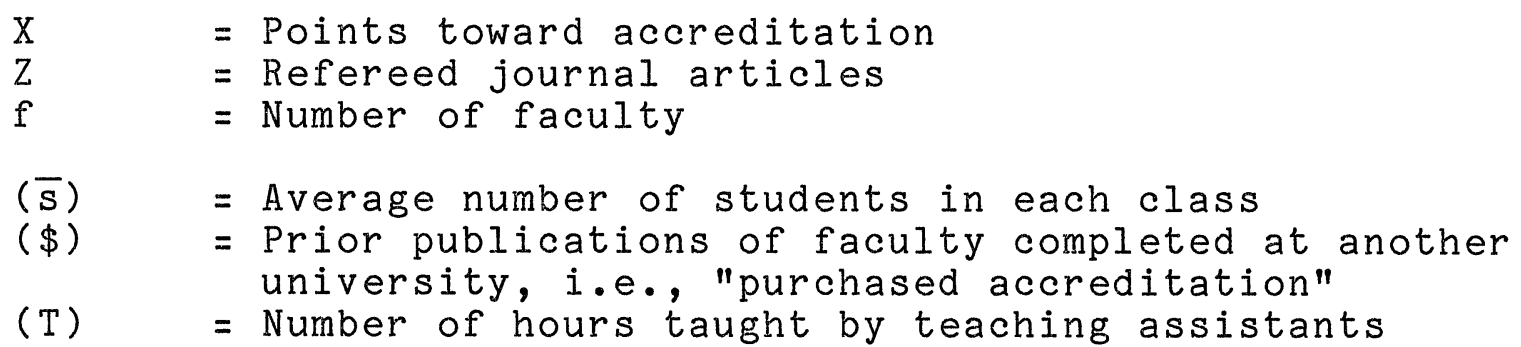

$X=\Sigma$

$[\mathrm{Z} / \mathrm{f}(\overline{\mathrm{S}})(\$)(\mathrm{T})]$

(I) (C) ( H ) (A)

$(I)=$ Indicator variable for innovative curriculum

1. Clone of all universities giving doctoral degrees

2. Some diversity based on student interest, strength of faculty

3. Imaginative, new, different concepts

$(C)=$ Indicator variable for classroom teaching techniques

1. No discussion, interaction, $100 \%$ of grade determined by $M / C$ tests. Courses taught by videotape to save faculty time and encourage students not to relate to faculty member as a real person

2. Some interaction permitted

3. Interaction of ideas among students and faculty encouraged - students required to communicate their progress through oral and written assignments

$(H)=$ Number of hours taught per full-time faculty member

$(A)=$ Number of hours faculty spend advising, counseling students 
not leave the class only knowing that response (C) was the right choice on the exam?"

"And, why aren't the faculty members advising students about their career choices so that students will have an opportunity to make an educated decision about the next forty years of their lives?"

"Willie, that is all in the formula, but our priorities have changed, we simply minimize (I) times $(\mathrm{C})$ times $(\mathrm{H})$ times (A) and maximize ( $\mathrm{Z}$ ) divided by (f) times bar (s).

"Then what are WE going to do about this 'n-demonstrated scholarly productivity which is essential for overall high quality of our business program' that is blocking our AACSB accreditation?"

"Do you mean YOUR un-demonstrated scholarly productivity?"

Suddenly the telephone went dead. This was followed by a knock at my door. Just as suddenly, there was Willie.

He shoved a letter (19), under my nose. It was from an AACSB associate director of accreditation and was written to our dean.

"Here. Right here." He pointed to a particular sentence.

"Not we Willie, you. I am refereed. Two articles per year for three years in the top tier business publications."

"And that makes you a higher quality than me? Look, I published too--a study guide for Management 300, an article in our own Arizona Business and Economic Review and I did that economic forecast in one of those nonrefereed journals."

"Willie, we are talking refereed. Besides, good teaching is an output and we need to be talking input--refereed publications input."

"So, your door is to be shut to students so that you do not waste your time with them? When did you start spending more time sitting behind your PC than standing in front of a classroom and interacting with students?"

I was still trying to make sure my (Z) over (f) times bar (s) times a big (\$) times $(\mathrm{T})$ over $(\mathrm{I})$, times $(\mathrm{C})$, times $(\mathrm{H})$, times $(\mathrm{A})$ maximizing $(\mathrm{X})$ was logical.

"But our teaching is more serious than refereed publications (15) and your stupid formula. We have a dedicated faculty; a well-prepared mission and scope statement and accompanying objectives; a supportive central administration (he was reading from the AACSB Team Report). We are cited in a recent book Searching For Academic Excellence $(8,1986) . "$

"Willie, this is not a stupid formula. It is the basis of my next refereed publication."

"But this report $(12$, p.5) said that we have a relatively thorough set of development policies and practices. And do not forget that we have a thirtytwo foot long glass case full of faculty publications. And it states right here (Willie pointed to the report again) that we have a well managed and pleasant library facility; a beautifully designed and fully adequate building, classrooms, administrative offices and other service offices beautifully designed and fully adequate for the present programs; and a special program which is aimed at attracting Native Americans from around the country for the purpose of pursuing an MBA."

"I am aware of that," I told him. "But I am not up to dealing with a search for academic excellence until I find out whether my formula should be 'input' oriented as is the current AACSB approach or 'output' oriented as 
our college's original goals. Input and output are so different."

"So you are going to take our emphasis on good teaching seriously?"

"I did not say I was not going to take good teaching seriously. I said I was not going to take it at all. Refereed publications equal accreditation which equals tenure plus raises. So I am working on my next refereed publication. I need time for these things. Give me another month and then I might tilt from refereed publications to good teaching."

"What about the other faculty? A month could be too late. We have to do something about it now!"

"No need to worry. The administration is going to hire the equivalent of one of those deans from an accredited graduate business school and ask him to bring five of his properly refereed faculty with him. In just one scoop we will have a built-in and properly refereed faculty. I should think that would take care of the matter."

"That dean will insist that everyone will need two refereed publications per year. I am afraid that I and most of our existing faculty will be gone in two years. Hey, I am not getting any younger. I cannot be moving from institution to institution just because I am not refereed."

"I hear you. So what the acting dean is planning to do this year is to take the $\$ 350,000$ the president is to allocate to the College and hire five new faculty members that are already refereed. With a little tenure, a little release time, a choice of classes, and salaries higher than anyone already on the staff, there should be no problem. Hey, at $\$ 60,000$ a piece and the right promises, we should be accredited by next fall."

"That might get us accredited, but what about me and others like me who are un-tenured and not properly refereed? We will be denied tenure and our positions will be used to attract properly published people."

"Willie, they would not do that. Right down to the last one of you, you are dedicated to this University and NO university dumps on dedication."

"Hey big Richard, you had better get real! When it comes to accreditation and probation, it is catch as catch can!"

"Willie, you are forgetting that NAU was listed in the top ten by Money Magazine (17, p.198) as one place that undergraduates could get a quality, Ivy League type education."

"Words are not enough. We are going to have to take some anti-accreditation action."

"Willie, do you have a mouse in your pocket? There is just so much a person in my position can do. Besides, everyone knows that undergraduates benefit from good instruction more than good reading; that student advising is the sole reason that our drop-out rate has leveled off; that good teaching stops good research; that small undergraduate classes beat large graduate assistant oriented classes; that most undergraduate students being taught by non-refereed faculty are not handicapped at all; and that graduating and getting a job is all that is important for the typical undergraduate student. But the name of this game is scholarly research."

"But don't you realize that emphasizing excellence via teaching the undergraduate business student is a dagger thrust in the heart of AACSB?"

"I am no dummy, Willie. Everyone knows that. But I have enough on my plate right now. The president is going to handle AACSB alone. I am sure he 
is up to it."

"But the faculty and students are starting to climb the wall because all they see is instruction by the nonrefereed. No student will ever make it to the job market. Are you going to stand by and allow this act of real world aggression?"

"Willie, you know how I feel about real world aggression. I was one of the first to speak out against it long before it was fashionable. At the same time, I have to deal with one crisis at a time. I cannot spread myself too thin."

"I am sorry you feel this way about it, " he said. "I was hoping you would at least have a solution to this one-maybe even suggest that AACSB is not for everyone, especially a university that built its reputation on 'to become educated is to become more human'. This CBA faculty will go crazy if they think that all their teaching efforts of the past have gone unnoticed."

"Willie, when it comes to refereed publications and AACSB, I do not believe I am the only one who is tuned in. I have spoken to a dozen faculty and many students and each one of them does not want probation. No one wants us to tell students that if they want refereed faculty that they should go to Harvard or Stanford."

"That is it then," Willie said. "You are just going to sit in your office and work on your formula while students knock and go away? Getting a promotion, a raise and accreditation via refereed publications is more important than students?"

"If you think it will do any good," I told him, "I will complete my research on my formula and get it refereed. Then I will take it to a print shop and have it printed on glossy, pocket-sized cards and have it distributed to every student and faculty member in the College to remind them of their College's new guiding principles. Picture this! It will start with, 'To become refereed is to become more human.' This will become a key ingredient of our changing organizational culture. And for good measure I will see that it is enlarged and bronzed for suitable display in the case where all the publications and the two bronze AACSB letters are. We will then be in the real world with an organizational culture of our own. This organizational culture--shared values, beliefs and rituals--stuff is great. We can have a new culture by Monday."

\section{REFERENCES}

1. "Accountable to Whom? Views of the Modern Business School" AACSB Newsline, February 1987 (Vol. 17, No. 3), pp. 3-13.

2. Agor, Weston H. Intuitive Management: Integrating Left and Right Brain Management Skills. Englewood Cliffs, N.J.:Prentice Hall, 1984.

3. American Assembly of Collegiate Schools of Business. Accreditation Council Policies Procedures and Standards. 1986-87.

4. American Assembly of Collegiate Schools of Business. Membership Directory 1986-87.

5. College of Business Administration, Northern Arizona University. AACSB Reaccreditation Self-Study Report. Volume I and Volume II. Flagstaff, Arizona: Northern Arizona University, June 1, 1986. 
6. Letter from John S. Day, President, American Assembly of Collegiate Schools of Business, St. Louis, Missouri, April 29, 1977.

7. Gazzaniga, Michael S. The Social Brain: Discovering the Networks of the Mind. New York: Basic Books, 1985.

8. Gilley, J.Wade, Kenneth A. Fulmer and Sally J. Reithlingshoefer. Searching for Academic Excellence. New York: American Council on Education/Macmillian Publishing Company, 1986.

9. Hickman, Charles, Director of Projects and Members, AACSB. Personal Telephone Interview. 18 May 1987.

10.Letter from Cyril C. Ling, Managing Director, American Association of Collegiate Schools of Business, May 16, 1969.

11."NAU Business College Gets One-Year Reprieve by Accreditation Group." Arizona Daily Sun, April 19, 1987, p.1.

12.Northern Arizona University Visitation: Continuing Accreditation for College of Business Administration and Accreditation of Accounting. AACSB Team Report. December 1986. In the files of the Office of the Dean, College of Business.

13.Peters, Thomas J. and Robert H. Waterman Jr. In Search of Excellence: Lessons from America's Best-Run Companies. New York: Harper and Row Publishers, 1982, p.60, 285.

14.Remus, William. "Strategies for a Publish or Perish World or Why Journals Are Unreadable." Interfaces, November 1977 (Vol.8, No.1) pp.64-69.

15.Sargent, Robert E. A Bug of Some Importance. New York: Charles Scribner, 1967.

16.Springer, Sally P. and Georg Deutsch. Left Brain, Right Brain. Revised Edition. San Francisco: W.H. Freeman \& Co., 1985.

17.Stickney, John. "Ten Public Colleges With an Ivy Twist." Money Magazine, May 1986 (Vol.15, No.5), pp. 192-200.

18. Memorandum from Joe Walka. Dean, College of Business Administration, Northern Arizona University, Flagstaff, Arizona, January 16, 1987.

19.Letter from Richard Wines. Associate Director Accreditation, American Assembly of Collegiate Schools of Business, St. Louis, Missouri, March 23, 1987.

20.Young, Kenneth E. and others. Understanding Accreditation. San Francisco: Jossey-Bass Publishers, 1983. 